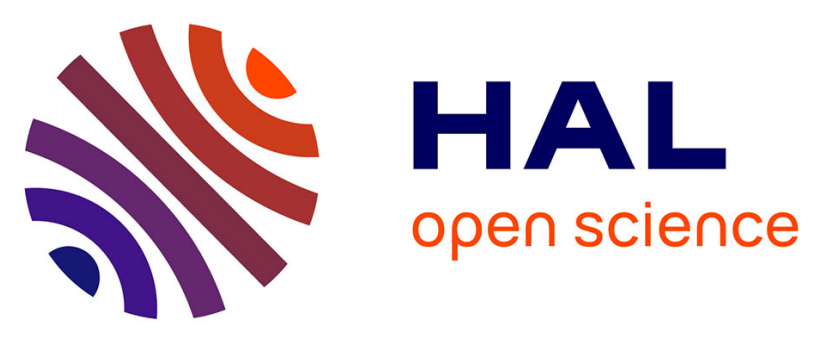

\title{
Local Structure and Dynamics in Methylammonium, Formamidinium, and Cesium Tin(II) Mixed-Halide Perovskites from 119 Sn Solid-State NMR
}

Dominik J Kubicki, Daniel Prochowicz, Elodie Salager, Aydar Rakhmatullin, Clare P Grey, Lyndon Emsley, Samuel D Stranks

\section{To cite this version:}

Dominik J Kubicki, Daniel Prochowicz, Elodie Salager, Aydar Rakhmatullin, Clare P Grey, et al.. Local Structure and Dynamics in Methylammonium, Formamidinium, and Cesium Tin(II) MixedHalide Perovskites from 119 Sn Solid-State NMR. Journal of the American Chemical Society, 2020, 142 (17), pp.7813-7826. 10.1021/jacs.0c00647 . hal-03000541

\section{HAL Id: hal-03000541 https://hal.science/hal-03000541}

Submitted on 19 Nov 2020

HAL is a multi-disciplinary open access archive for the deposit and dissemination of scientific research documents, whether they are published or not. The documents may come from teaching and research institutions in France or abroad, or from public or private research centers.
L'archive ouverte pluridisciplinaire HAL, est destinée au dépôt et à la diffusion de documents scientifiques de niveau recherche, publiés ou non, émanant des établissements d'enseignement et de recherche français ou étrangers, des laboratoires publics ou privés. 


\section{Local structure and dynamics in methylammonium, formamidinium} and cesium tin(II) mixed-halide perovskites from ${ }^{119} \mathrm{Sn}$ solid-state

\section{NMR}

Dominik J. Kubicki, ${ }^{\mathrm{a}, \mathrm{b}}$ Daniel Prochowicz, ${ }^{\mathrm{d}}$ Elodie Salager, ${ }^{\mathrm{f} g \mathrm{~g}}$ Aydar Rakhmatullin, ${ }^{\mathrm{f}}$ Clare P. Grey*b, Lyndon Emsley*c, Samuel D. Stranks*a,h

${ }^{a}$ Cavendish Laboratory, Department of Physics, University of Cambridge, IJ Thomson Avenue, Cambridge, CB3 OHE, UK Department of Chemistry, University of Cambridge, Lensfield Road, Cambridge, CB2 1EW, UK

Laboratory of Magnetic Resonance, Institute of Chemical Sciences and Engineering, Ecole Polytechnique Fédérale de Lausanne (EPFL), CH-1015 Lausanne, Switzerland

Institute of Physical Chemistry, Polish Academy of Sciences, Kasprzaka 44/52, 01-224 Warsaw, Poland

Conditions Extrêmes et Matériaux: Haute Température et Irradiation (CEMHTI), UPR 3079 CNRS, Université d'Orléans,

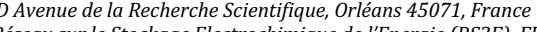

3459 CNRS, 33 Rue Saint Leu, Amiens 80039, France CB3 OAS, UK

Supporting Information Placeholder

ABSTRACT: Organic-inorganic tin(II) halide perovskite ave emerged as promising alternatives to lead halide perovconsiderably poorer performance and stability as compare to their lead analogues, their performance improvemen to a critical lack of methods to probe their atomic-level micrstructure. Here, we identify the challenges and devise a ${ }^{119}$ solid-state NMR protocol for the determination of the local ovskites as well as their and misation products allide pephases. We establish that the longitudinal relaxation of 1195 can span 6 orders of magnitude in this class of compound which makes judicious choice of experimental NMR param ters essential for relable detection of various phases. We alloys in any ratio, while only limited mixing is possible for I/Cl compositions. We elucidate the degradation pathways of CS-, MA- and FA-based tin(II) halides and show that degrad regardless of the A-site cation and halide. We detect the pres ence of metallic tin amongst the degradation products, whic we suggest could contribute to the previously reported hig conductivities in tin(III) halide perovskites. ${ }^{119}$ Sn NMR chenvironment as well as of the A-site cation composition. Finally. we use variable-temperature multi-field relaxation measur ments to quantify ion dynamics in $\mathrm{MASnBr}_{3}$, establish activation energles for motion and show that this motion leads to whenever two different pure-halide perovskites are put physical contact. a widely investigated problem in the field of lead halide peovskite photovoltaics since chloride doping leads to signicantly improved thin film crystallinity and carrier diffusion leported for chloride doping in tin (II) halide perowskite based solar cells.28,29 However, to the best of our knowledge, here is no direct evidence for $\mathrm{I} / \mathrm{Cl}$ mixing in the case of tin(II)

Another strategy to stabilize tin(II)-based materials is the mbine the advantageous optoelectronic properties lead-based materials while providing band gaps of $1.2-1.3$ thite tandem solar cells.30-34

The resulting materials are typically probed using diffractheir electronic properties. However, the atomic-level effect of various additives cannot be evaluated since there are curmulti-component tin(II) halide perovskites. Rapid deture tion of tin(II) halide perovskites has been consistently observed in device studies, $35-37$ and degradation mechanism have been investigated using XRD, TGA and UV-Vis spectro . main elusive.

Solid-state NMR has recently been shown to be the metho of choice to determine local structure and dynamics in lead halide perovskites, which are uniquely amenable owing to the particular, solid-state NMR can be used to evide of $\mathrm{A} / \mathrm{B}-$ site cation incorporation,, $39-45$ halide mixing, ${ }^{46-49}$ doping-induce phase segregation processes, $40,4,1,43,46$ to study interfacial pas (a) erovskites has been previously investigated in $\mathrm{CsSn} \mathrm{Br}_{3}$ $\mathrm{MASnI}_{3}{ }^{62}$ and $\mathrm{FASnI}_{3}{ }^{62}$ using pair distribution function (PDF) analysis. Given the prevalence of tin NMR studies of other roups of materials, it is surprising that it has not yet bee em is not trivial. To the best of our knowledge the only example of applying solid-state MAS NMR to tin halide perovskites to date is a $1 \mathrm{H}$ MAS NMR study of cation mixing idex de perovskites, $46-4,60$ and hence it is expected that tin NMR should be well suited to study tin analogues as well as mixed n-lead materials.

Tin has three NMR-active isotopes: $115 \mathrm{Sn}$, $117 \mathrm{Sn}$ and ${ }^{119} \mathrm{~S}$ All three isotopes have spin I $=1 / 2 \%$ and similar roromanetc ratios which renders ${ }^{119}$ Sn the most receptive of the three, with a receptivity ca. 27 times that of ${ }^{13}$ C. Solid-state tin NM has been widely employed to study organotin compounds, tors ${ }^{73-75} \mathrm{Tin}$ NMR is particularly sensitive to the difference between the $+27,7,7$ and +478 oxidation state with the corresponding chemical shifts differences on the order of sever bound to the tin site. $119 \mathrm{Sn}$ chemical shifts span the range be tween 1000 and $-2000 \mathrm{ppm}$ for diamagnetic compounds an $7000-8000 \mathrm{ppm}$ for tin metal. 79 Much larger ranges of shifts
Here, we probe the atomic-level microstructure of singleand mixed-halide (I, Br, Cl) tin(II) halide perovskites, sing dites and tin(IV) notion (Cs, MA, FA) tin(II) halide peror NMR spectroscopy. We show that iodide-bromide and bro mide-chloride mixtures form solid solutions for any I/Br and $\mathrm{Br} / \mathrm{Cl}$ ratio. On the other hand, iodide-chloride composition while partially miscible, yield phase segregated mixtures of
phases. We show how 119 Sn MAS NMR can be applied to study degradation pathways of tin(II) halide perovskites and th degradation typically leads to highly disordered $\mathrm{SnO}_{2}$ an alostannates(IV). We have also detected traces of metallic tin in the degraded material. Three of the degradation prod of $-4818 \mathrm{ppm},-4684 \mathrm{ppm}$ and $-4518 \mathrm{ppm}$, respectively, va ues unprecedented in their magnitude for diamagnetic tin compounds. Further, we show that $1195 n$ longitudinal relaxa 列 sential for reliable detection of various phases. Finally, we use variable-temperature multi-field ${ }^{119}$ Sn MAS NMR to quantify halide dynamics in $\mathrm{MASnBr}_{3}$ and show the

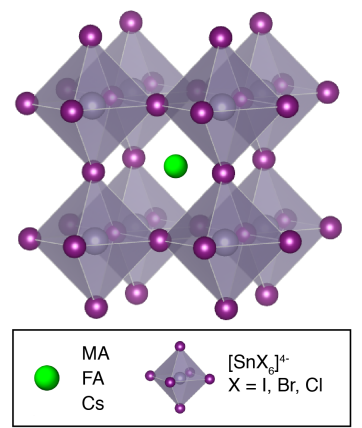

Figure 1. Schematic representation of the crystal structure of tin(II) halide
octahedra.

Experimenta

Materials. The following materials were used: methylammo98\%), formamidinium bromide (Sigma 98\%) (Sigm midinium chloride (Sigma, 97\%), CsI (Fischer, 99.9\%), CsB (Fischer, 99.9\%), CsCl (Acros, 99.99\%), SnI2 ( Sigma,
99.999\%), SnBr2 (Sigma), SnCl2 (Sigma, 98\%), Snl (Sigma, 999\%) $\mathrm{SnBr}_{4}$ (Sigma $99 \%$ ).

Perovskite mechanosynthesis. The materials were pre pared using mechanosynthesis80,81 following recently pubon. The halostannates were synthesized by grinding the re-
ond ctants in an electric ball mill (Retsch MM-400) using at $25 \mathrm{~Hz}$. XRD parterns $\mathrm{SEM}$ i ball $(810 \mathrm{~mm}$ ) for $30 \mathrm{minut}$ nochemical tin(II) halide perovskites have been previously 
reported 82,83 and agree with those recorded on materials prepared as single crystals and thin films. The quantities of re-

NMR measurements. Solid-state MAS NMR spectra of $119 \mathrm{~S}$ (7.7. strength. About 200-250 mg of sample was used for each ceasure delays were set based on the measured $T_{1}$ values, as $d e$ MAS and room temperature ${ }^{14} \mathrm{~N}(36.2 \mathrm{MHz})$ experiments were recorder on a Bruker Avance III $11.7 \mathrm{~T}$ spectrometer wo 3.2 miz low-temperatus CPMAS probe us1ing previously optimized parameters. 39 High-temperature $4.7 \mathrm{~T}$ spectrometer $(74.7 \mathrm{MHz}$ ) using a $4 \mathrm{~mm}$ MAS Bruker probe ( $\mathrm{MgO}$ stator) in the range between $308 \mathrm{~K}$ and $455 \mathrm{~K}$ us ing $4 \mathrm{~mm}$ zirconia rotors spinning at $5 \mathrm{kHz}$ with heated nitro(n). (279.7 MHz) using a MAS LASER probe (Bruker) with airtight boron nitride crucibles contained in $7 \mathrm{~mm}$ zirconia rotors spinning at $6 \mathrm{kHz}$. Temperature was adjusted using diode hyers of tive sample temperature through the $79 \mathrm{Br}$ shift of $\mathrm{KBr} .66 .87 \mathrm{In}$ order to prevent any interactions between $\mathrm{KBr}$ and the peovskite sample, a thin layer of PTFE tape was placed in be were used to mitigate ringing effects. CSA parameters were ftted using TopSpin 3.5. Further experimental details are given in the SI.

\section{Results and discussion}

Local structure of mixed-anion tin halostannates

Figure 2 shows ${ }^{119} \mathrm{Sn}$ solid-state MAS NMR spectra of menates(II), bromostannate(IV) as well as their tin(II) and in(IV) halide precursors recorded at room temperature. The ${ }^{119 S n}$ chemical shitt is highly sensitive to the local environ-
ment of the tin site and makes it possible to distinguish tin(II) precursors - $\mathrm{SnCl}_{2}(-916 \mathrm{ppm}$, fig. $2 \mathrm{za})$ and $\mathrm{SnBr}_{2}(-640 \mathrm{ppm}$ $\left(-398\right.$ ppm, fig. 2c) and $\mathrm{MASnBr}_{3}$ (-316 ppm (fig. 2g). MASnCls exhibits successive phase transitions at 283,307 , MAr and $463 \mathrm{~K}$. slightly distorted $\left[\mathrm{SnCl}_{6}\right]^{4-}$ octahedra which leads to the presence of chemical shift anisotropy (CSA) manifesting itself as set of spinning sidebands (SSB) spaced by the MAS rotatio (1) ported. ${ }^{88}$ Replacing $\mathrm{Cl}^{-}$with $\mathrm{Br}$ - in $\mathrm{MASnCl}_{3}$ leads to solid solutions for the full range of $\mathrm{Cl} / \mathrm{Br}$ ratios studied here. Low $\mathrm{Br}$ concentrations, as in $\mathrm{MASnC}_{2.7} \mathrm{Br} \mathrm{Br}_{0}$, lead to a slight broade ing and the appears (fig of two the two sites correspond to diferent local $\left[\mathrm{SnBr}_{6} \times \mathrm{Cl}_{\mathrm{C}}\right]^{4}$ - environments within the same phase, where the bromide content is higher for the enviroAs the concentration of $\mathrm{Br}^{-}$- in the lattice is increas -393 presonance broadens further takes on a chemical shift intere resate with respect to $\mathrm{MASnCl}_{3}$ and $\mathrm{MASnBr} 3$ and its appare

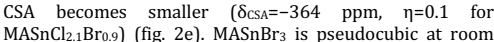

emperature so its $\delta \mathrm{csA}_{\mathrm{SA}} 0 \mathrm{ppm}$ and there are no SSBs associted with the main peak (fig. 2 g). ${ }^{36}$ The peak is significantly

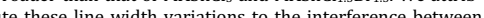
政 below (see also Supplementary Note 1). Note that this spectrum was acquired with no rotor synchronization in the very fast $T_{2}$ relaxation. Using a rotor-synchrorized due to ay $(83.3 \mu \mathrm{s})$ leads to lower SNR but does not lead to the apearance of SSBs (fig. S1). Further, 119Sn NMR makes it possible to distinguish between bromostannates(II) and (IV) While $\mathrm{SnBr}_{4}(-659 \mathrm{ppm})$ is shifted only slightly with respect $\mathrm{ppm})$ and $\mathrm{MA}_{2} \mathrm{SnBr}_{6}(-1990 \mathrm{ppm})$ is much more pronounced.

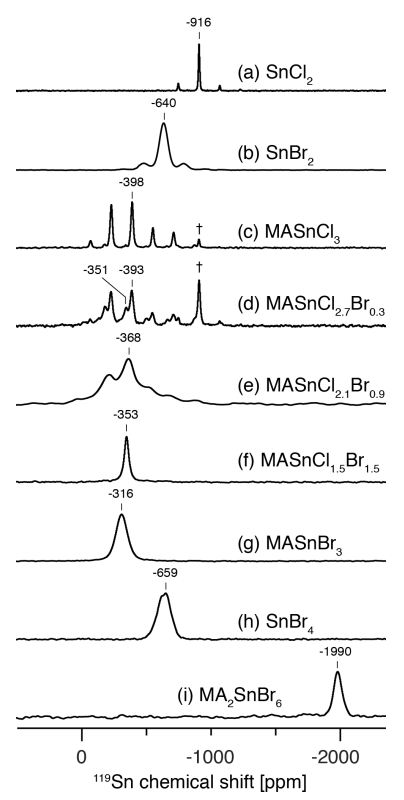

igure 2. ${ }^{119} \mathrm{Sn}$ solid-state MAS NMR spectra of mixed-anio (chloride/bromide) halostannates and their precursors at 4.7 , $12 \mathrm{kHz}$ MAS (except for $\mathrm{SnBr}_{4}$ ) and $298 \mathrm{~K}$ : (a) $\mathrm{SnCl}_{2}$, (b) MASnCl..5Br..5, (g) MASnBr3 (h) SnBr, (at $0.6 \mathrm{kHz}$ MAS top vent melting), (i) $\mathrm{MA}_{2} \mathrm{SnBr}_{6}$. indicates trace unreacted $\mathrm{SnCl}_{2}$ In turn, we investigate iodide-containing halostannate(II) and (IV) species. SnI 2 (-527 ppm fig. 3a) exhibits a partially resolved ${ }^{119} S \mathrm{n}-127 \mathrm{~s}$ scalar coupling, 1$]_{\mathrm{sn}-1}=6.2 \mathrm{kHz}$, similar in crystal structure of $\mathrm{MASnn} 3 \mathrm{~s}$ is pseudocubic at room tempera ture hence a symmetric peak with $\delta c s a \approx 0$ ppm is expected However, the material yields a very broad, slightly asymmet-
ic resonance with a $\mathrm{T}_{2}{ }^{2} \approx 10 \mu \mathrm{s}$ (estimated from the line width) which we attribute to very efficient scalar relaxation Similarly short $\mathrm{T}_{2}{ }^{*}$ has been previously observed in lead io-

igure 3c shows two ${ }^{119} \mathrm{Sn}$ spectra of $\mathrm{MASnCl}_{2} \mathrm{I}_{0.3}$ : one obighlight the iodide- and chloride-rich environments, re spectively. The signal corresponding to the iodide-rich phase shifted to lower frequencies (to lower ppm values) with re spect to pure MASnl (fig. $3 b$ ), which supports the formation on that Cl. can incorporate into the MASnl, perovskite lattice. On the other hand, the signal corresponding to the chloide-rich phase is identical, within experimental error, to tha in pure $\mathrm{MASnCl}$, (fig. $2 \mathrm{Cc}$ ) which indicates that I - has not bee sult can be rationalized conside radii of I- $(2.2 \AA)$ and $\mathrm{Cl}^{-}(1.8 \AA)$ which cause the MASnC structure to be more compact compared to that

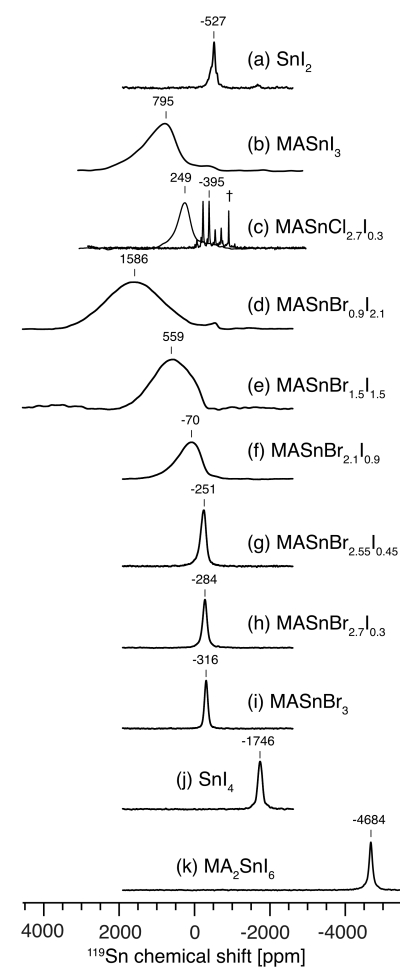

Figure 3. ${ }^{119} \mathrm{Sn}$ solid-state MAS NMR spectra of mixed-anion (odide/chloride and iodide/bromide) halostannates and MASnI (c) (c) MASnC.7 T, 12 ke signals at 249 and (a) $\mathrm{Snl}_{2}$, (b) 列 tively (d) MASnBro.9 2.1.1, (e) MASnBri.51..5, (f) MASnBr 21.109 , ( MASnBr 2.55lo.45, (h) MASnBr 2.70.3, (i) $\mathrm{MASnBr}_{3}$, (j) $\mathrm{Snl}_{4}$, (k

On the other hand, iodide-bromide mixing has been previ-

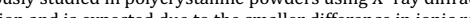
dii of $\mathrm{I}^{-}(2.2 \AA)$ and $\left.\mathrm{Br}^{-}(2.0 \AA)\right)^{36} \mathrm{As}^{-} \mathrm{I}^{-}$is replaced by $\mathrm{Br}^{-}$- in the crystal structure of $\mathrm{MASnl}_{3}(\mathrm{fig} .3 \mathrm{~b})$, the spectrum initially broadens and shifts to higher frequencies (to higher ppm val-

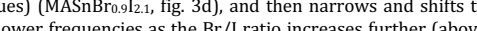
$\mathrm{Br} / \mathrm{I}=1.5: 1.5$, fig. 3e-f). Similar spectral trends have bee previously reported in ${ }^{119}$ Sn MAS NMR spectra of other disordered solids, such as stannate pyrochlores ${ }^{9}$ and in $207 \mathrm{~Pb}$ MAS Here however, we ascribe the strong line width varation to the different magnitudes of $127 \mathrm{I}$ and $79 / 81 \mathrm{Br}$-induced relaxation, as described in the next section.

The difference in chemical shift between $\mathrm{Sn}(\mathrm{II})$ and $\mathrm{Sn}(\mathrm{IV})$ iodides and iodostannates in even more pronounced than for bremsily ditio be same is true for $\mathrm{MASnl}_{3}\left(795 \mathrm{ppm}\right.$, fig. 3b) and $\mathrm{MA}_{2} \mathrm{Snl}_{6}$ $(-4684 \mathrm{ppm}$, fig. 3k). The latter $119 \mathrm{Sn}$ chemical shift is, to the best of our knowledge, the most shielded tin environment re strong deshielding (shift at high positive ppm values), the exact opposite is observed experimentally. This is due to the ems, as has been previously shown by fully-relativistic DFT calculations. 92 The $119 \mathrm{Sn}$-127 I scalar coupling constant in monn $\mathrm{Sn}_{4}$ has been previously found to be ${ }^{1} \mathrm{sn}_{\mathrm{sn}}=0.9 \mathrm{kHz}$ and not resolved in the solid state.9.

Local structure of FA, Cs and mixed A-site cation tin halostannates

The A-site cation composition, mixing and segregation in solid lead halide perovskite has been previously explored $d$ i-

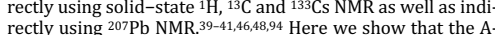
site composition in tin(II) halide perovskites can be probed
indirectly using $119 \mathrm{Sn}$ MAS NMR. Figure 4 shows 119 Sn MAS NMR spectra of single- and mixed-cation cesium, me All iodides yield very broad (full width at half maximu (fwhm) of 70-170 kHz) and largely featureless spectra due to very efficient scalar $T_{2}$ relaxation (fig. 4a-c). At room temperorthorhomis 6 . Whereas symmetric pected for highly symmetric structures, in this case the line shapes are asymmetric which suggests that they are not determined entirely by $T_{2}$ relaxation but rather that there is ancaused by the well-documented effect that a fast-relaxing quadrupolar nucleus has on the line shape of a spin-1/2 nucleus which is coupled to it.97 We were able to numerically simulate the line shapes and obtained a good qualitative tivity $1195 n$ spectra can be recorded for $3 \mathrm{D}$ tin iodide pero skite within minutes under the experimental conditions used 
here and while they are sensitive to the halide coordination environment, their value for investigating A-site cation mixovskite tin iodide phases ( $\mathrm{SnI}_{2}$, $\mathrm{SnI}_{4}$ and $\mathrm{MA}_{2} \mathrm{SnI}_{6}$ ) do not sufer from this complication, likely owing to their different crys. tal structure in wh.
nism is reduced.

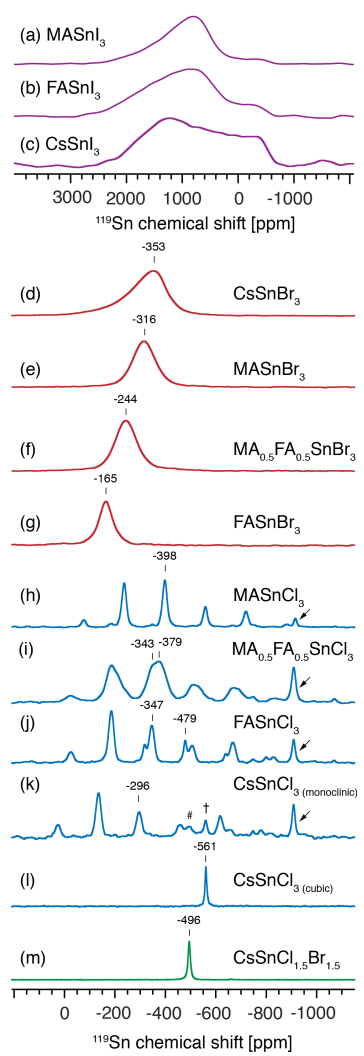

gure 4. ${ }^{119} \mathrm{Sn}$ as a probe of the A-site cation (Cs, MA, FA) and A-site cation mixing in tin(II) halide perovskites. $119 \mathrm{Sn}$
solid-state MAS NMR spectra at $4.7 \mathrm{~T}, 12 \mathrm{kHz}$ MAS (unless stated otherwise) and 298 Kof iodides: (a) MASnI3, (b) FASnI
(static, see fig 56 for $12 \mathrm{kHz}$ MAS) (c) CSSnI 3 ; bromides: (d) rides: (h) $\mathrm{MASnCl}_{3}$, (i) $\mathrm{MA}_{0.5} \mathrm{FA}_{0.5} \mathrm{SnCl}_{3}$, (j) $\mathrm{FASnCl}_{3}$, (k) CsSCll (monoclinic), Indicates the metastable cubic pha unit cell of $\mathrm{CsPbCl}_{3}$ (I) $\mathrm{CsSnCl}_{3}$ (cubic); mixed-halides: (m) $\mathrm{CsSnCl}_{1.5} \mathrm{Br}_{1.5}$. The arrows indicate trace unreacted $\mathrm{SnCl}_{2}$.
On the other hand, tin(II) bromide perovskites yield well-resolved spectra whereby the chemical shift is a sensitive fin-

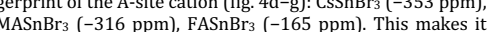
possible to probe A-site cation mixing using $119 \mathrm{Sn}$ NMR in the bromide systems. For example, $\mathrm{MA}_{0.5} \mathrm{FA}_{0.5} \mathrm{SnBr}_{3}(-244 \mathrm{ppm})$ yields a sn chemical shift which is intermediate with recorrelation between the MA/FA ratio and the ${ }^{119} \mathrm{Sn}$ c chemical shift in $\mathrm{MA}_{\mathrm{x}} \mathrm{FA}_{1-\mathrm{x}} \mathrm{SnBr}_{\mathrm{B}}$ : $\mathrm{\delta}_{\mathrm{sn}}(\mathrm{ppm})=-151 \cdot \mathrm{x}-166$. All four materials exist in the highest symmetry cubic $\alpha$-phase at room numerically solso iso in this case, the line broadening was numerically simulated and is attributed to fast quadrupolar

Tin(II) chloride perovskites typically exist as low-symmetry $\mathrm{CsSnCl}_{3}$ and $\mathrm{MASnCl}$, respectively98,99) hence they yield characteristic CSA patterns (fig. 4h-l). Also in this case the ${ }^{119}$ S cation and an additional constraint is provided by the observed (298 K) CSA parameters: MASnCl3 ( $\delta_{\text {iss }}=-398 \mathrm{ppm}$, $\left.\delta_{C s A}=-435 \mathrm{ppm}, \quad \eta=0.26\right), \quad \mathrm{FASnCl}_{3} \quad\left(\delta_{\text {iso }}=-347 \mathrm{ppm}\right.$, $\left.\delta_{\mathrm{CAA}}=-508 \mathrm{ppm}, \eta=0.06\right), \quad \mathrm{CsSnCl}_{3}\left(\delta_{\mathrm{sis}}=-296 \mathrm{ppm}\right.$,

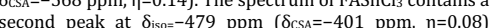
which likely corresponds to a second tin(II) site inside the asymmetric unit cell, analogous to the situation observed in the low-symmetry phase of MASncl3.0 A-site cation mixing $\mathrm{MA}_{0} \mathrm{FA}_{0} \mathrm{SnCl}$ : the resonances broaden considerably and the two broad components (FA: $\delta_{\text {iso }}=-343, \delta \delta_{C A}=-510 \mathrm{ppm}$, $\eta=0.01$ and MA: $\delta_{i s 0}=-379 \mathrm{ppm}, \delta_{\mathrm{css}}=-353 \mathrm{ppm}, \eta=0.12$ ) take on values intermediate with respett to the single-cation phase $(\delta$ iso $=-561 \mathrm{ppm}, \delta \mathrm{cs} \sim 0 \mathrm{ppm})$ at room temperature if the sample is briefly heated to $380 \mathrm{~K}$ (fig. 41). This phase is metastable and can be transformed back to the low-symmetry phase in the presence of humidity. Finally, we note ronment in tin(II) halides perovskites not only when the Asite is an organic cation (fig. 2 and 3) but also when it is an Inorganic cation such as cesium. Figure $4 \mathrm{~m}$ shows that the diate with respect to the cubic phase of $\mathrm{CSSnCl}(-561 \mathrm{ppm})$ and $\mathrm{CsSnBr}_{3}(-353 \mathrm{ppm})$. Taken together, these findings demonstrate that 119Sn MAS NMR is well-suited for probing the atomic-level microstructure of mixed-cation and mixedboth the A-site and X-site composition. The 119Sn data can be complemented by ${ }^{13} \mathrm{C},{ }^{14} \mathrm{~N}$ and ${ }^{133} \mathrm{CS}$ NMR measurements to evaluate the local structure and dynamics of the A-site, as dis-

\section{Degradation pathways}

Having established a comprehensive database of ${ }^{119} \mathrm{Sn}$ shifts for various relevant tin halide perovskite materials, we now figure 5 shows a compsis $\mathrm{MASnBr}$, $\mathrm{FASnBr}_{3}$, $\mathrm{CsSnBr}_{3}$, MASnI 3 , FASnl 3 and $\mathrm{CsSn}_{3}$. The degradation was performed ex situ in air and the degradation conditions (temperature and duration) were chosen phepounds, as monitored by the disappearance of the pristine perovskite ${ }^{119}$ Sn signal.

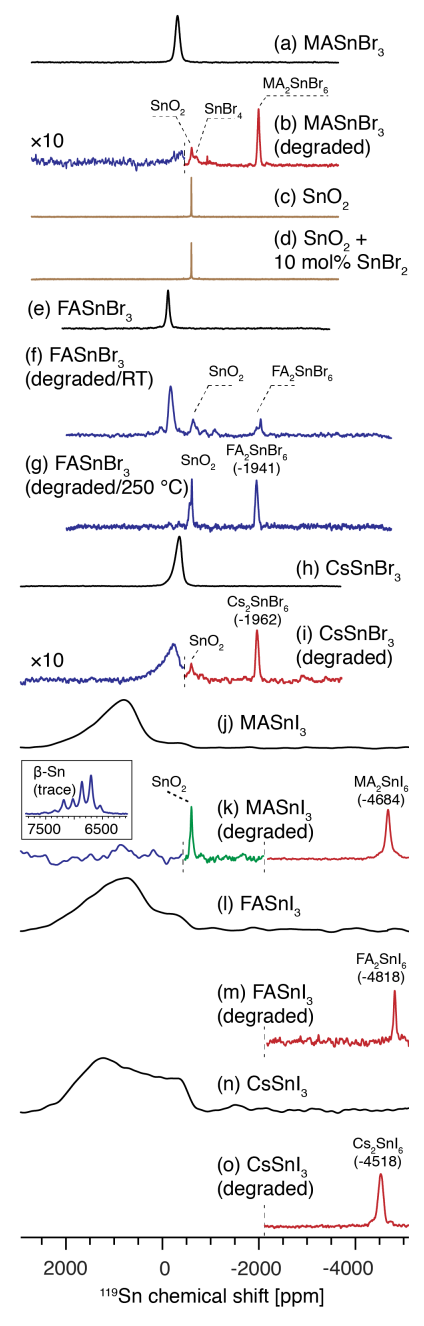

Figure 5. ${ }^{119} \mathrm{Sn}$ as a probe of tin(II) halide perovskite degradaand $298 \mathrm{~K}$ of (a) $\mathrm{MASnBr}_{3}$ (as prepared), (b) $\mathrm{MASnBr}_{3}$ (dgraded for $1 \mathrm{~h}$ at $250^{\circ} \mathrm{C}$ in air), (c) $\mathrm{SnO}_{2}$, (d) $\mathrm{SnO}_{2}+10 \mathrm{~mol} \%$

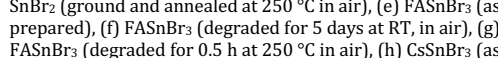

prepared), (i) $\mathrm{CsSnBr}_{3}$ (degraded for $0.5 \mathrm{~h}$ at $350^{\circ} \mathrm{C}$ in air), ( () MASnl 3 (as prepared), (k) MASnl 3 (degraded for $1 \mathrm{~h}$ at $150^{\circ} \mathrm{C}$

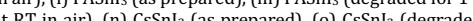
for $3 \mathrm{~h}$ at $100^{\circ} \mathrm{C}$ in air). The dashed lines indicate points at acquired at different transmitter offsets were stitched together: b, i (two offsets), k (three offsets). For m The Thermal degradation $\left(1 \mathrm{~h}\right.$ at $250^{\circ} \mathrm{C}$ in air) of $\mathrm{MASnBr}_{3}$ (fig. 5a) leads to a mixture of $\mathrm{MA}_{2} \mathrm{SnBr}_{6}, \mathrm{SnO}_{2}, \mathrm{SnBr}_{4}$ and trace to an ionic product of the reaction between tin(II) and decomposition products of the organic cation. Interestingly, the $\mathrm{SnO}_{2}$ signal in the degraded perovskite is significantly broader (fwhm: $3.5 \mathrm{kHz}$ ) compared to neat microcrystalline during decomposition is locally highly disordered This could be caused by bromide doping 100 or amorphization. We exclude bromide doping as the reason for the observed disorder, since a $\mathrm{StO}_{2}$ mechanchemically doped with $\mathrm{SnBr}_{2}$ and cess, did not lead to broadening of the $\mathrm{SnO}_{2}$ resonance (fis. 5d). We therefore conclude that the $\mathrm{SnO}_{2}$ formed during the degradation of tin(II) halides perovskites is poorly crystal-
line, or forms as nanodomains. We note that this would likely render its detection challenging by XRD.

We also observed that degadtion leads to qualitatively similar products as high-temperature degradation. However, the products formed at room temperture are considerably more locally disordered. Room-tenleads to very broad peaks of $\mathrm{Sn}_{2}$ (fwhm: $\sim 10 \mathrm{kHz}$ ) as well a $\mathrm{FA}_{2} \mathrm{SnBr}_{6}$ (two components, $3-6 \mathrm{kHz}$ ) (fig. 5 f). After 5 days of exposure to ambient laboratory air, the sample of microcrys-
talline FASnBrs still contains a large amount of the non-degraded perovskite ( $\sim 45 \%$ of the initial content). Degradatio phase and renders the peaks narrower $\left(\mathrm{SnO}_{2}\right.$ : two components, fwhm $2-3 \mathrm{kHz}, \mathrm{FA}_{2} \mathrm{SnBr} 6$ : : fwhm $4 \mathrm{kHz}$ ), presumably as result of thermal annealing (fig. 5g). Similarly, in the case formation of $\mathrm{SnO}_{2}$ and $\mathrm{Cs}_{2} \mathrm{SnBr}_{6}$ (fig. 5 h-i).

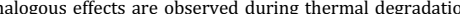
of $\mathrm{MASnI}_{3}$ (fig. 5j-k) as well as $\mathrm{FASnI}_{3}$ (fig. 5l-m) and CsSnl (fig. 5n-0), which yield $\mathrm{FA}_{2} \mathrm{Sn}_{16}(-4818 \mathrm{ppm})$ and $\mathrm{Cs}_{2} \mathrm{Sn}_{6}$ XRD diffraction on the degraded materials, which showder the presence the oxidized $\mathrm{A}_{2} \mathrm{SnX}_{6}$ species (fig. S12). In addition, we note that we have detected metallic $\beta$-Sn in the sample of degraded $\mathrm{MASnl}_{3}$ (fig. $5 \mathrm{k}$, inset) which, however, is only presition times). The anisotropic Knight shift of the $\beta$-Sn impurity is consistent with that of a reference $\beta$-Sn powder sample $\left(\delta_{\text {iso }}=6864 \mathrm{ppm}\right.$ or $\left.0.68 \%, \delta_{\text {aniso }}=486 \mathrm{ppm}, \eta=0.1\right)$ and with the values previously reported for metallic tin powder ${ }^{101,1}$ an additive to increase the stability of FASnl 3.16 We suggest that the presence of metallic tin in tin(II) halide perovskites among the degradation products may contribute to the high conductivity values previously reported in the literature for niquely to self-doping. The formation of $\mathrm{SnO}_{2}$ and $\mathrm{SnX}_{4}$ has been shown in a recent TGA study, ${ }^{103}$ which corresponds to the state in which the organic component has been fully vo- 
latilized. Solid-state ${ }^{119}$ Sn NMR carried out on materials degraded under similar conditions refines this picture by show
ing that the degradation proceeds through an intermediate which is the coresponding tin(IV) halostannate A S S X conclusions of our study are therefore fully consistent with those of Leijtens et al.103 Based on these observations, we conclude that ${ }^{119} \mathrm{Sn}$ MAS is well-suited for studying degradatio

Optimal experimental conditions for ${ }^{119} \mathrm{Sn}$ NMR detection One of the most important considerations associated with the acquisition of $119 \mathrm{Sn}$ MAS NMR data of tin(II) halides pero${ }^{119}{ }^{11}$ n longitudinal relaxation times $\left(T_{1}\right)$ can span 6 that magnitude (fig. 6). This makes it essential to carefully adjus the experimental parameters so as to ensure optimal sensitivity and/or quantitativeness. The physical reason behin nating relaxation mechanism in diffe pounds. $T_{1}$ relaxation in tin halides has been shown to be largely due to the ${ }^{119} \mathrm{Sn}-\mathrm{X} \mathrm{X}$ scalar coupling whereby the relax ation rate depends on the coupling strength. odostannates, intermediate in bromostannates and slowest in chlorostannates. ${ }^{78,93}$ This trend is clearly visible exper mentally (fig. 6, blue). Beyond the coupling strength, the effithe coupling is modulated (e.g. by fast relaxation of the hal gen or chemical exchange). If these processes are not fast enough relative to the coupling strength, other mechanism such as CSA or dipolar driven relaxation may prove more ef$\mathrm{MA}_{2} \mathrm{SnBr}_{6}$ since these compounds have considerably longer T's as compared to the corresponding iodo- and bromostar

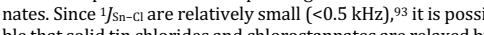
ble that solid tin chlorides and chlorostannates are relaxed by $(\beta-S n)$ is driven by the conduction electrons, as shown by Korringa. ${ }^{104}$ In the next section, we elucidate the relaxation mechanism for ${ }^{119} \mathrm{Sn}$ in $\mathrm{MASnBr}$ and show that it is inde

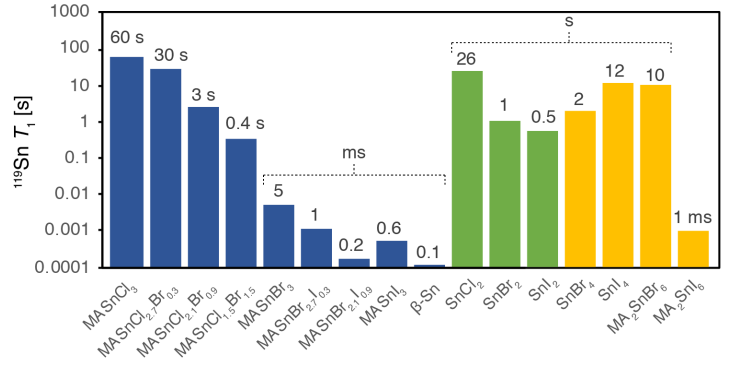

Figure 6. ${ }^{19} \mathrm{Sn}$ longitudinal relaxation times $\left(T_{1}\right)$ at $4.7 \mathrm{~T}, 298 \mathrm{~K}, 12 \mathrm{kHz}$ MAS (except for $\mathrm{SnBr} 4$ which was measured at $0.6 \mathrm{kHz}$ MAS to prevent melting) of the tin(II)- and tin(IV)-containing phases investigated in this work. Blue: tin(II) halide perovskites, green: in(II) halides, yellow: tin(IV) halides and halostannates(IV). The numerical values are reported in table S3

Halide dynamics in $\mathrm{MASnBr}_{3}$

TMR relaxation in solids is caused by fluctuating magnetic
We note that the fast scalar relaxation does not affect the nurelaxation therefore has no effect on the A-site cation, which MAS NMR, as we and others groups have previously shown or lead halide perovskites. $39-42,45,53,55,56$ Figure $S 2$ shows lowtemperature ${ }^{1-13} \mathrm{C} C \mathrm{CP}$ spectra of methylammonium tin(II) mA in the mixed-halide perovskites. The ${ }^{13} \mathrm{C}$ resonance of to single halide compositions due to halide disorder. The ${ }^{13} \mathrm{C}$ resonances fall within a similar chemical shift range which makes the use of ${ }^{119} \mathrm{Sn}$ considerably more advantageous ure S3 shows room-temperature $1{ }^{14} \mathrm{~N}$ MAS spectra of MASnI

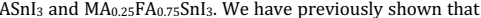
the width of the ${ }^{14} \mathrm{~N}$ SSB manifold is related to the cubooctahedral symmetry in lead halide perovskites, with narrower 政 in(II) halide perovskites. For example, the MA and FA SSB manifolds broaden in $\mathrm{MA}_{0.25} \mathrm{~F}_{0.75} \mathrm{Sn}_{3}$ compared to the singedral symmetritions indicating that the overall cubooctaing, similar to the effect previously observed in mixed-cotion erature ${ }^{133}$ Cs spectra of $\operatorname{CSSn} X_{3}(\mathrm{X}=\mathrm{I}, \mathrm{B}$, CI). The signals are narrow (fwhm 90-110 Hz) and well-resolved which potenent mixing and phase segregation processes in Cs-containing tin halide perovskites, similarly to how it has previously
been shown in the context of lead halide perovskites. 40

therefore be used to study dynamic processes with timescales ranging from picoseconds to seconds. 105 We demonstrate this in MASnBr3. The following mechanisms can in principle cause ${ }_{19}$ Sn relaxation in solids: (a) dipole-dipole interaction, 106 (b) (c) Raman p oce scalar relaxation.10

order to elucidate which mechanism is relevant in MASnBr 3 , we acquired variable-temperature $T_{1}$ relaxatio data at three magnetic field strengths: $4.7 \mathrm{~T}, 9.4 \mathrm{~T}, 17.6 \mathrm{~T}$, and The CSA mechanism has a strong field dependence he an be excluded. Dipole-dipole relaxation leads to a $T_{1}$ minimum in the range of seconds $(\sim 5 \mathrm{~s})$, hence this mechanis can also be excluded (see Supplementary Note 2 for the calculation). The Raman process leads to $T_{1}$ values which are inportional to the square of the temperature, neither of which is the case here (fig. S5). MAS-induced heteronuclear polarzation exchange arises due to crossing between energy level

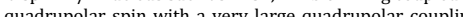
constant, which is the case for ${ }^{127} \mathrm{I}$ and $79 / 81 \mathrm{Br}$. In this mechanism, the $T_{1}$ is significantly reduced when the sample is spun.
We did not observe $T_{1}$ shortening between the static and spinning case (fig. S6). Finally, scalar relaxation is expected to ${ }_{119} \mathrm{Sn}-79 / 81 \mathrm{Br}$ scalar coupling either due to chemical exchange (scalar relaxation of the first kind) or fast quadrupolar relaxphysical origin of the process can be dectermined f. $106 \mathrm{Th}$ temperature dependence of the $T_{2}$ relaxation times, which de crease with increasing temperature if they are caused by relaxation of the quadrupolar nucleus and increase with temperature if they are caused by chemical exchange, provide he system is in the slow motion limit, both processes lead to onger ${ }^{119} \mathrm{Sn} T_{2}$ as the temperature increases (see also Supplementary Note 3). We use fwhm of the ${ }^{119} \mathrm{Sn}$ signal as a meas

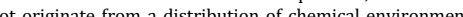
(i.e. $T_{2}^{*} \approx T_{2}$ ) Experimentally, we observe that the ${ }^{119} \mathrm{Sn}$ resonances become narrower as the temperature increases (fig 7 a and table S1) which shows that $T_{2}$ increases with tempe rupolar partner is not straightforward in this case due to its very large quadrupole coupling constant, ${ }^{110}$ we employ the determined activation energy as a constraint to identify the relevant relaxation mechanism. Plotting $\ln \left(119 \mathrm{Sn} T_{1} / \mathrm{s}\right.$ ) as (fig. 7b) from which we determine the activation energy of the process driving the relaxation (table 1 and S2). Averaging the results obtained at three magnetic fields and between $250-450 \mathrm{~K}$, we obtain an average activation energy of ( 36 agreement with those previously found for bromide diffusio in $\mathrm{MASnBr}$ using ac and dc conductivity measurements $(0.30$ and $0.31 \mathrm{eV}$, respectively). ${ }^{11,1112}$ This value is also comparable to those previously reported for halide diffusion in $\alpha$-Sn that $T_{1}$ relaxation of ${ }^{119} \mathrm{Sn}$ in $\mathrm{MASnBr} 3$ is primarily driven by scalar relaxation of the first kind, i.e. by movement of species inside the crystal lattice. Scalar relaxation of the second kin ponding to the process driving quadrupolar relaxation $79 / 81 \mathrm{Br}$, i.e. vibrational modes of the lattice, which are active in the far infrared to terahertz regime $(<0.03 \mathrm{eV}) .113,114$
tin halides are ionic conductors, 115 we conclude that the chemical exchange process which drives ${ }^{119} \mathrm{Sn}$ relaxation in MASnBr 3 is the diffusion of $\mathrm{Br}$ - ions in the crystal lattice. Ionic halide perovslites 57.116 and tin halies. 1151117 Thes 列 culations predict a formation energy of $0.37 \mathrm{eV}$ for iodide va-

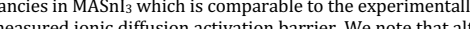
ough these two processes are not equival Went halde nigttion relies on the presence of halide vacancies 118 . Sin MASnBr 3 starts decomposing above $\sim 420 \mathrm{~K}$ and there is no 11 minimum in the accessible temperature range, it was not the halide diffusion rate. We note, however, thas the prever ously calculated halide hopping rates are in the nanosecond range in lead halide perovskites. ${ }^{119,1}$

Fnally, we show that the comparatively low activation energy for halide diffusion leads to spontaneous halide mixin atrom temperature
119 Sn MAS NMR.

able 1. Activation energies $\left(E_{a}\right)$ for halide migratio in tin(II) halide perovskites and related phases.

\begin{tabular}{|c|c|c|c|c|}
\hline Material & $\begin{array}{l}\begin{array}{l}\mathrm{E}_{\mathrm{a}} \\
{[\mathrm{kJ} / \mathrm{mol}]}\end{array} \\
\end{array}$ & \begin{tabular}{|l|}
$E_{a}$ \\
{$[\mathrm{eV}]$}
\end{tabular} & Technique & Ref. \\
\hline $\begin{array}{l}\mathrm{MASnBr}_{3} \\
(4.7 \mathrm{~T})\end{array}$ & $\begin{array}{|ll|}42.7 & \pm \\
0.5 & \\
\end{array}$ & 0.44 & \multirow{4}{*}{$\begin{array}{l}\text { solid-state } \\
\text { NMR }\end{array}$} & \multirow{4}{*}{$\begin{array}{l}\text { this } \\
\text { worl }\end{array}$} \\
\hline $\begin{array}{l}\mathrm{MASnBr}_{3} \\
(9.4 \mathrm{~T})\end{array}$ & $\begin{array}{|ll|}31.9 & \pm \\
0.1 & \\
\end{array}$ & 0.33 & & \\
\hline $\begin{array}{l}\mathrm{MASnBr}_{3} \\
(17.6 \mathrm{~T})\end{array}$ & $\begin{array}{|ll|}34.1 & \pm \\
0.1 & \end{array}$ & $\mid 0.35$ & & \\
\hline $\begin{array}{l}\text { MASnBr } 3 \\
\text { (aver- } \\
\text { age) }\end{array}$ & $36 \pm 6$ & $\begin{array}{l}0.37 \pm \\
0.06\end{array}$ & & \\
\hline $\mathrm{MASnBr}_{3}$ & 29.1 & 0.30 & ac conductivity & 111 \\
\hline $\mathrm{MASnBr}_{3}$ & 30 & 0.31 & dc conductivity & 112 \\
\hline$\alpha-\mathrm{SnI}_{2}$ & 28 & 0.29 & ac conductivity & 115 \\
\hline $\mathrm{MASnI}_{3}$ & 63 & $\begin{array}{l}0.37 \\
\left(V_{1}\right) \\
0.65 \\
(1 ;) c\end{array}$ & DFT & 118 \\
\hline $\mathrm{MAPbl}_{3}$ & $28 \pm 6$ & $\begin{array}{l}0.29 \pm \\
0.06\end{array}$ & \begin{tabular}{|l} 
transient \\
ion-drift
\end{tabular} & 116 \\
\hline $\mathrm{MAPbI}_{3}$ & 16 & \begin{tabular}{|l|l|}
0.17 \\
\end{tabular} & $127 \mathrm{I} Q \mathrm{R}$ & 57 \\
\hline
\end{tabular}

The iodide vacancy. $\mathrm{I}_{-}$- iodide interstitial. 

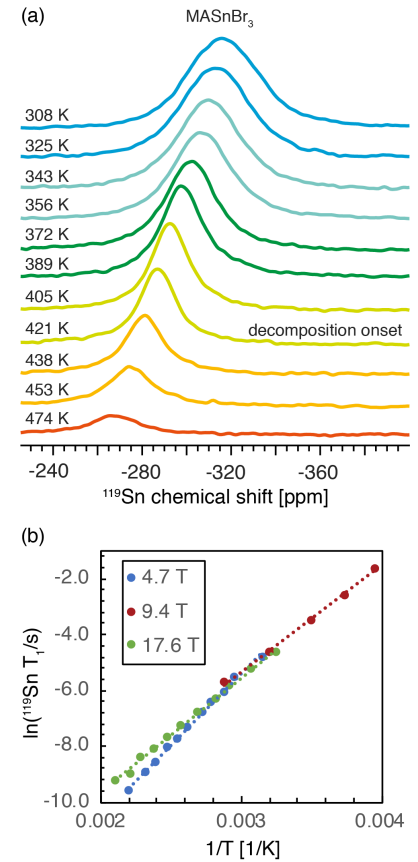

Figure 7. Halide dynamics in MASnBrs from multi-field variable-temperature ${ }^{119} \mathrm{Sn}$ solid-state MAS NMR. (a) variaspectra were acquired using the same number of scans
(4096) and are quantitative. The spectrum after thermal de (4096) and are quantitative. The spectrum after thermal de-
composition corresponds to $\mathrm{MA}_{2} \mathrm{SnBr}_{6}$ (fig. $4 \mathrm{~b}$ ) with traces of composition corresponds to $\mathrm{MA}_{2} \mathrm{SnBr}$ r (fig. $4 \mathrm{~b}$ ) with traces of
$\mathrm{SnO}_{2}$ as discussed above. (b) An Arrhenius plot of the ${ }^{119} \mathrm{Sn} T$ relaxation data at $4.7 \mathrm{~T}$ (blue), $9.4 \mathrm{~T}$ (red) and $17.6 \mathrm{~T}$ (green)
The linear fits are indicated by dotted lines and the numerical values are given in table $\mathrm{S} 2$.

\section{Spontaneous halide mixing}

Thermally activated halide mixing has been previously demonstrated in microcrystalline46 lead halide perovskites and in polycrystanine thin we physically mixed equimolar amounts of microcrystalline $\mathrm{MASnBr}_{3}$ (fig. 8a, - $316 \mathrm{ppm}$ ) and $\mathrm{MASnCl}_{3}$ (fig. 8b, -398 ppm) by weighing the materials into a vial and turning the vial up orded after 24 hours of storing the mixture under a room temperature shows that the single-halide perovskites have fully disappeared and a new chemical species has formed (fig. 8c,d). Recording a spectrum with a short recycte environments (-325 ppm, fig. 8c) while using a long recydo delay accentuates the slowly relaxing chloride-rich environments $(-340 \mathrm{ppm}$, fig. 8d). The resulting mixed-halide perovppm, fig. 8e) although the slight difference in ch.5B 1.5 $(-353$ (1) pect these results to carry over to other tin(II) halide perovskite compositions and suggest that spontaneous halide mixentration gradient

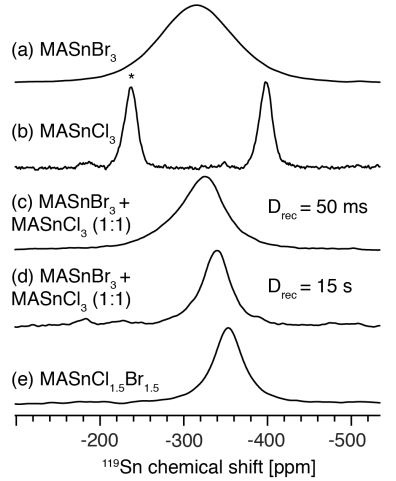

Figure 8. ${ }^{119} \mathrm{Sn}$ as a probe of spontaneous halide mixing. ${ }^{119 S \mathrm{Sn}}$ $\mathrm{MASnBr}_{3}$, (b) $\mathrm{MASnCl}_{3}$, the asterisk indicates a spinning sideband (c) 1:1 (mol $/ \mathrm{mol})$ mixture of $\mathrm{MASnBr}_{3}$ and $\mathrm{MASnCl}_{3}$, $50 \mathrm{~ms}$, (d) same as (c) but using a recycle delay of $15 \mathrm{stoh}$ highight the slowly relaxing chloride-rich environments, (e) $\mathrm{MASnCl}_{1.5} \mathrm{Br}_{1}$

Conclusions

We have identified and overcome the challenges associated with the acquisition of solid-state $119 \mathrm{Sn}$ MAS NMR data, namely that the londudnal relaxation of $\mathrm{Mn}$ in tin(II) halnitude, which makes it essential to judiciously choose the experimental parameters so as to obtain optimal results. We have shown that solid-state ${ }^{119}$ Sn MAS NMR can be used to charactense he locl strute of (II) mixed-halde and to distinguish between tin(II) and tin(IV) halostannate phases. This property in particular can be employed to study degradation processes in tin(II) halide perovskites and we

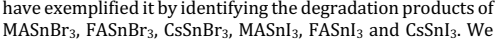
have found that regardless of the composition, the decomposition products include amorphous $\mathrm{SnO}_{2}$ and the corresponding tin(IV) halostannate, $\mathrm{A}_{2} \mathrm{SnX}_{6}$. Further, we have identified MASnBrs as scalar relaxation of the first kind driven by bromide diffusion inside the perovskite lattice. We have quantified the activation energy of this process using variable-temperature multi-field relaxation measurements and found that from previously reported electrical conductivity measurements. Finally, we have shown that spontaneous halide hooystanization occuss at row temperature between microads to mixed-halide materials. We expect this property of tin(II) halide perovskite to carry over to other tin(II) halide perovskites systems featuring a halide concentration grad-

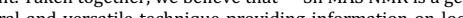
列 entary to the data obtained by diffraction techniques an optical spectroscopies.

\section{Associated Content}

Supporting Information

Supplementary information (additional ${ }^{119} \mathrm{Sn}, 13 \mathrm{C}, 133 \mathrm{CS}$ an tails), is available in the online version of the paper. Requests for additional data and correspondence should be addressed to C.P.G, L.E. or S.D.S.

\section{Author Information}

\section{Corresponding Author}

*cpg27@cam.ac.uk

*sds65@cam.ac.uk

Notes

SDS is a co-founder of Swift Solar, Inc.

\section{Acknowledgement}

This work has received funding from the European Union's 政 work was supported by Swiss National Science Foundatio

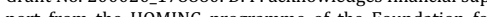
Polish Science co-financed by the European Union under the European Regional Development Fund (POlR.04.04.00-005EE7/18-00). Financial support from the IR-RMN-THC The Tata Group (UF150033).

\section{References}

(1) Li, W.; Wang, Z.; Deschler, F.; Gao, S.; Friend, R. H.; Cheetham

A.K. Chemically Diverse and Multifiunctional Hybrid Organic-
Inorganic Perovskites. Nat. Rev. Mater. 2017, 2, 16099 .

(2) Jena, A. K: Kulkarni, A; Miyasaka, T. Halide Perovskite Photovoltaics: Background, Status, and Future Prospects. Chem. Rev
2019,
119 https://doi.org/10.1021//acs.chemrev.8b00539. Kojima, A.; Teshima, K; Shirai, Y: M Miyasaka, Tsutomu. Organ-
ometal Halide Perovskites as Visible--ight Sensitizers for ometal alide Perosskites as Visble-tight
Photovoltaic Cells.J.Am . Chem. Soc. 2009, $131,6050-6051$.

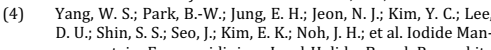
Layers for Efficient Solar Cells. Science 2017, 356 (6345)

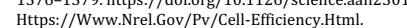

(5) Domanski, K; Alharbi, E. A; Hagfeldt, A;; Grätzel, M; ; Tress, W. Systematic Investigation of the Impact of Operation Condtions on the Degradation Behaviour of Perovskite Solar Cells
Nat. Nat Energy 2018,3
https://doi.org $/ 10.1038 / 541560-017-0060-5$.
(7) Tress, W; Domanski, K;; Carlsen, B;; Agarwalla, A; Alharbi, E.

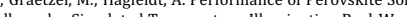
perating Conditions. Nat. Energy 2019, 4 (7), 568-574.

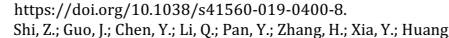
W. Lead-Free Organic-Inorganic Hybrid Perovskites for Photovoltaic Applications: Recent Advances and Perspectives.
Adv. Mater. 2017, $29 \quad(16), 1605005$. Adv. Mater 2017, 29 (16), 1605005.
https://doi.org/10.1002/adma.201605005.

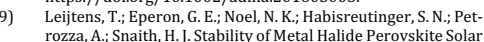

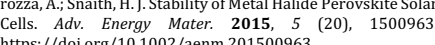

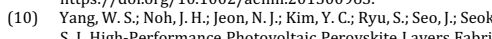

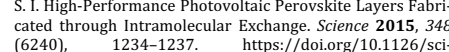

(11) Abdi-alebi, M; Andai-Garmaroudi, Z; Cacovich, S:; Stavrakas

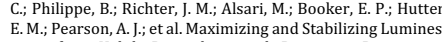
cence from Halide Perovskites with Potassium Passivatio
Nature 2018 555.

(12) Lee, S. J; Shin, S. S.; Kim, Y. C.; Kim, D; A Ahn, T. K; Noh, J. H. Seo Seok, S.I. Fabrication of Efficient Formamidinium Tin 1 J. Am. Chem. Soc. 2016, 138 (12), 3974-3977.

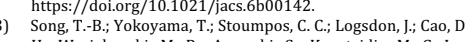

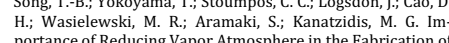
portance of Reducing Vapor Atmosphere in the Fabrication of
Tin-Based Perovskite Solar Cells. I. Am. Chem. Soc. 2017, 139

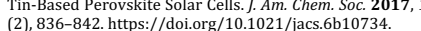

(14) Tsarev, S.; Boldyreva, A. G;: Luchkin, S. Y.; Elshobaki, M.

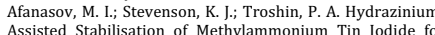

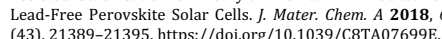

(15) Li, F; ; Zhang, C.; Huang, J.-H; ; Fan, H; Wang, H; Wang, P; Z Zhan

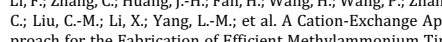

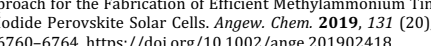

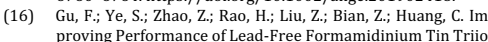
proving Performance of Lead-Free Formamidinium Tin Triil-
dide Perovskite Solar Cells by Tin Source Purification Sol RRL
S 2018, $\quad 2 \quad(10), \quad 1800136$

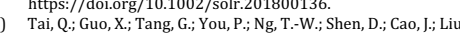

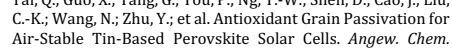
131 1319. $316-820$

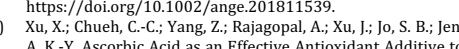

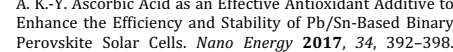

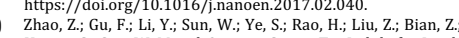
Huang, C: Sun, W. Mixed-Organic-Cation Tin Iodide for LeadFree Perovskite Solar Cells with an Efficiency of 8.12. Adv. Sci.
Weinh. Baden-Wurt. Ger. 2017, 4 (Copyright (C) 2018 U.S.

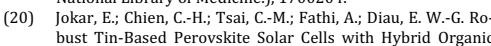
Cations to Attain Efficiency Approaching 10\%. Adv. Mater
Cont 2019, $31 \quad$ (2), 1804835 .

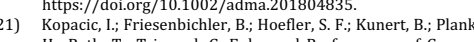

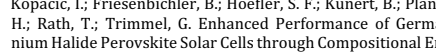
gineering. ACS Appl. Energy Mater. 2018, 1 (2), 343-347.
https://doi.org/10.1021/acsaem.8b00007 
(22) Liu, Ji; Ozaki, M.; Yakumaru, S; Handa, T.; Nishikubo, R. Kanemitsu, Y; Saeki, A; Murata, Y; Murdey, R; Wakamiya, with High Coverage and Improved Aggregation. Angew. Chem
2018,

23) Shao S S L tur

ten; Koster, L., I. A... Loi, M. A. Highly Reproducible Sn-Based
Hybrid Perovskite Solar Cells with $9 \%$ Efficiency. Adv. Energ hybrid Perovskite Solar Cells Mater
https://doi.org/10.1002/aenm.201702019.

(24) Stranks, S. D.: Eperon, G. E; G Grancini, G;: Menelaou, C; Allocer ron-Hole Diffusion Lengths Exceeding 1 Micrometer in an ganometal Trihalide Perovskite Absorber. Science 2013, 342

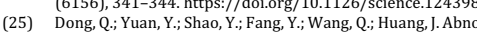
列 Solution Coating Process. Energy Environ. Sci. 2015, 8 (8)
$2464-2470$. https://doiorg $10.1039 / C 5 E F 011795$

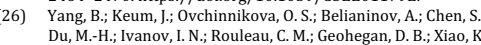
Deciphering Halogen Competition in Organometallic Halide

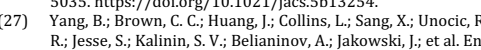
lancing Ion Migration in Grain Boundaries of Hybrid Organichorganic Perovskites by Chiorine. Adv. Funct. Mater. 2017,2

Marshall, K. P.; Walker, M.; Walton, R. I.; Hatton, R. A. Ehanced Stability and Efficiency in Hole-Transport-Layer--rree
Cssnl3 Perovskite Photovoltaics. Nat. Eneray 2016, 1,16178 . csSnl3 Perovskite Photovoltaics. Nat. Energy 2016, 1, 1617
https://doi.org/ 10.1038/NENERGY.2016.178.

Marshall, K. P.; Walton, R. Li; Hatton, R. A. Tin Perovskite/Fullerene Planar Layer Photovoltaics: Improving the Efficicien
and Stability of Lead-Free Devices. I. Mater. Chem. A 2015 (21), 11631-11640. https://doi.org/10.1039/c5ta02950c.

(30) Eperon, G. E.; Leiltens, T.; Bush, K. A; Prasanna, R;; Green, R; e tal. Perovskite-Perovskite Tandem Photoovotaics with
Optimized Band Gaps. Science 2016, 354 (6314), 861-865.

(31) Prasanna, Ri, Gold-Parker, A; Leitens, T.; Conings, B.; Ba-

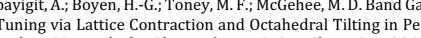
139kite Materials for Photovoltaics. J. Am. Chem. Soc. 2017. https://doi.org/10.1021/jacs.7b04981.
Zhao, B; Abdi-alebi, M.; Tabachnyk, M

.

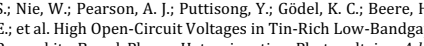
Perovskite-Based Planar Heterojunction Photovoltaics. Ad

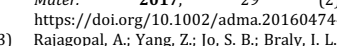

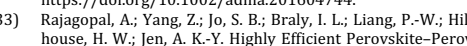
skite Tandem Solar Cells Reaching $80 \%$ of the Theoretica Limit in Photovoltage. Adv. Mater. 2017, 29 (34), 170214

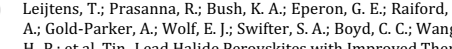
1.-P; , et al. Tin-Lead Halide Perovskites with Improved TheCells. Sustain. Energy Fuels 2018, 2 (11), 2450-2459.

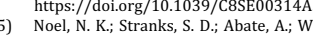

nera, S.; Haghighirad, A.A.A; Sadhanala, A.; Eperon, G. pathak, S. Ki; Johinstan B.; et al. Lead-Free Organic-lno-

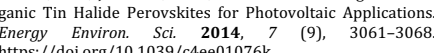

(36) Hao, F; Stoumpos, C. C.; Cao, D. H.; Chang, R. P. H.; Kanatzidis G. G. Lead-free Sold State Organic-horganic Halde Perov-

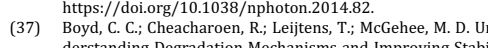

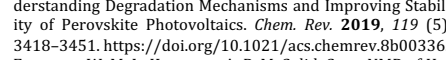

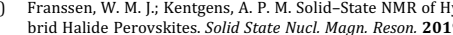
100, 36-44. https://doi.org/10.1016/j.ssnmr.2019.03.005.

(39) Kubicki, D.j.;; Prochowicz, D.; Hofstetter, A;; Péchy, P; Zake-

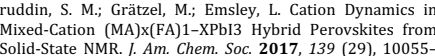

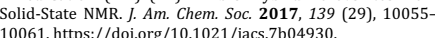

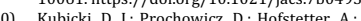

M; Grätzel, M;: Emsley, L. Phase Segregation in Cs: Rb-and K-

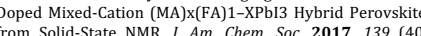
14173-14180. https://doi.org/10.1021/jacs.7b07223.

(41) Kubicki, D.J;; Prochowicz, D.; Hofstetter, A; Saski, M.; Yadav et al. Formation of Stable Mixed Guanidinium-M ethylamm nium Phases with Exceptionally Long Carrier Lifetimes for

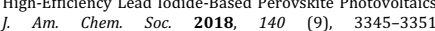
https://doi.org/10.1021/jacs.7b12860.
Kubicki. D. I: Prochowicz, D. Hofstetter, A; Zakeeruddin,

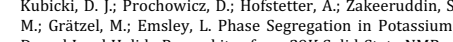
Doped Lead atilide Perovskites from $39 \mathrm{~K}$ Solid-State enMR a
21.1 T. I. Am. Chem. Soc. 2018, 140
(23), 7232-7238. 21.1 T. J. Am. Chem. Soc. 2018, 140 (23), 7232-7238
https: //doio.org/10.1021/jacs.8b03191.

(43) Kubicki D. I Prochowicz D. Pinon A

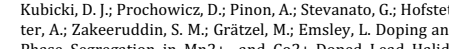
Phase Segregation in Mn2+- and Co2+-Doped Lead Halide ment. J. Mater. Chem. A 2019, $7, \quad 2326-2333$.

https://doi.org/10.1039/C8TA11457A.

(44) Xiang, W; Wang, Z; Kubicki, D. Ji; Tress, W.; Luo, Ji; Prochow-
icz, D; Akin, S; Emsley, L; Zhou, I.; Dietler, G; is tal. Europium

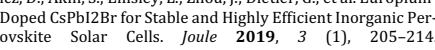
https:///doiororg/10.1016/ijijule.2018.10.008.

(45) Frasssen, W. M. . I.; Bruijnaers, B. J.; Portengen, V. H. L.;
Kentgens, A. P. M. Dimethylammonium Incorporation in Lead Kentgens, A. P. M. Mimethylammonium Incorporation in Lea
Acetate Based MAPbi3 Perovskite Solar Cells. ChemP Physchem
3107-3115. ho18, 19 / 19 (22), rrganolead Mixed-Halide Perovskites. Chem. Mater. 2016, 28 6848-6859.

(47) Karmakar, A; Askar, A. M: B; Bernard, G. M.; Terskikh, V. V: Ha Synthesis of Methylammonium Lead Mixed-Halide Perier Sythesis of Methylammonium Lead Mixed-Halide Perol-
skites: Unraveling the Solid-Solution Behavior Using SolidState NMR. Chem. Mater. 2018, 30, 2309-2321.

(48) Askar, A. ...; Karmakar, A; Bernard, G. M.; Ha, M.; Terskikh, V. V.: Wiltshire, B. D.; Patel, S; Fieet, I. Shankar, K.; Michaelis,
K. Composition-Tunable Formamidinium Lead Mixed Halide coding the Pb Environments Using Solid-State NMR Spectros.
copy. J. Phys. Chem. Lett. 2018, 9, 2671-2677.

Hanrahan, M. P.; Men, L; Rosales, B. A.; Vela, Ji; Rossini, A. . Sensitivity-Enhanced 207Pb Solid-State NMR Spectrosco lead Halide Perovskites. Chem Mater 2018, 30 (20) 7005-

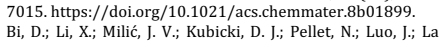

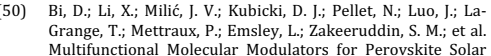

Cols with over 20\% Efficiency and High Operational Stability. https://doi.org/10.1038/s41467-018-06709-w.

(51) Alharbi, E. A; Alyamani, A. Y; Kubicki, D. J; Uhl, A. R.; Walder

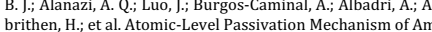
$\begin{array}{lll}\text { Nat. Commun } & \text { 2019, } 10 & \text { (1), }\end{array}$

https: //doi.org/10.1038/s41467-019-10985-5.
Tavakoli M. M. Tress, W. Milić, J V. Kubichi D.

Grätzel, M. Addition of Adamantylammonium Iodide to to Hol Transport Layers Enables Highly Efficient and Electrolum(11),3310-3320. https://doi.org/10.1039/C8EEO2404A

(53) Wasylishen, R.E.; Knop, O.; Macdonald, ,. B. Cation Rotation

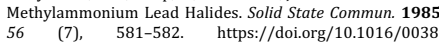

(54) Knop, O:; Wasylishen, R. E; White, M. A; Cameron, T. S.; Va Oort, M. J. M. Alkylammonium Lead Halides. Part
CH3NH3PbX3 ( $=$ Chlorine, Bromine, Iodine) Perovskites Cuboctahedral Halide Cages with Isotropic Cation Reorienta-
tion. Cann. J. Chem. 1990) 68 (Copyright (C) 2018 American
Chemical Society (ACS). All Rights Reserved.), $412-422$.

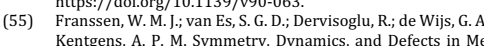
thylammonium Lead Halide Perovskites. J. Phys. Chem. Lett.
2017,
$61-66$.

(56) hertps://doi.org/10.1021/acs.jpclett.6b02542. Wu, Q.; Buriak, I. M:; Hauger, T. Methylammonium Cation Dynamids in Methylammonium Lead Halide Perovskities:
solid-State NMR Perspective. $J$. Phys. Chem. A 2018, 122 (6).
$150-1533$.

1560-1573. https://doi.org/10.1021/acs.jpca.7b11558.

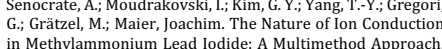
Chem. Int. Ed. 2017, 56, 7755-775.

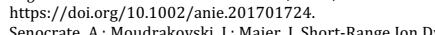
namics in Methylammonium Lead Iodide by Multinuclear
Solid State NMR and 1271 N NQRR. Physs. Chem. Chem. Phys 2018
20 https://doi.org/10.1039/C8CP01535.

9) Senocrate, A; Moudrakovski, L.; Acartürk, T;; Merkle, R; Kin in CH3NH3Pbis under Light Measured by Solid-State NM and Tracer Diffusion. J. Phys. Chem. C 2018, 122 (38), 21803

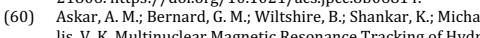
lis, V. K. Multinuclear Magnetic Resonance Tracking of Hydro,
Thermal, and Hydrothermal Decomposition of CH3NH3Pbl3.

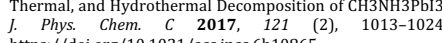

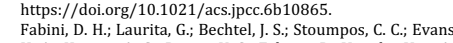

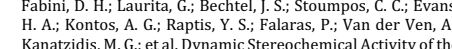
Sn2+ Lone Pair in Perovskite CSSnBr3.J. Am. Chemm Soc. 2016,
$11820-11832$
(36),

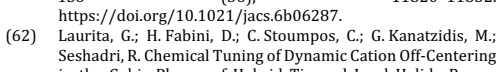

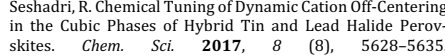
hhttps://doiem. 10.1039 .

(63) Ferrara, C. Patrini M. Pisanu A. Quadrelli, P.; Milanese, $C$ Tealdi, C; Malavasi, L. Wide Band-Gap Tuning in Sn-Based Hy-
brid Perovskites through Cation Replacement: The FA(1x) MA(x)SnBr(3) Mixed System.J. Mater. Chem. A 2017, 5 (19)

(64) Wrackmeyer, B.Application of $1195 \mathrm{~S}$ NMR Parameters. In $A n$

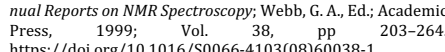

(65) Clayden, N. Ji; Dobson, C. M.; Fern, A. High-Resolution Solid-

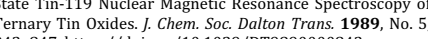
843-847. https://doi.org/10.1039/DT9890000843.

(66) Grey, C. P.; Dobson, C. M. . Cheetham, A. K; J Jakeman, R. J. B.
Studies of Rare-Earth Stannates by Tin-119 MAS NMR. The

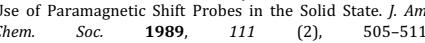

(67) Lin, Z:; Rocha, I.: Jesus, J. D. P. P. de; Ferreira, A. Synthesis and Structure of a Novel Microporous Framework Stannosilicate.
Mater. Chem. 2000, 10 (6), 1353-1356

8) Ferreira A: Lin. Z: Rocha J: Morais C M: Lopes M. Ferna dez, C. Ab Initio Structure Determination of a Small-Pore (14),3330-3335. https//doior / / 101021/ic0o12571,

(69) Wolf, P.; Valla, M; Rossini, A. J., Dri; Comas-Vives, A., Dr

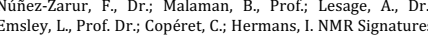
on the Active Sites in Sn- - Z Zeolite. Angew. Chem. Int. Ed . 2014,
(38). 53
https://doi.org/10.1002/anie 201403905. 10179-1018

(70) Mundus, C.; Taillades, G; Fradel, A; Ribes, M. A 119Sn Solid-

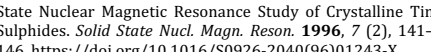

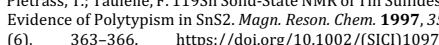
458x(199706)35:6<363::AID-OMR79>>3.0.CO:2-P. P.

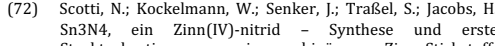

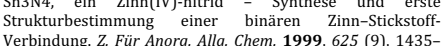
Verbindung. Z. Für Anorg. Allg. Chem. 1999, 625 (9), 1435-
https://doi.org/10.1002/(SICI)1521-

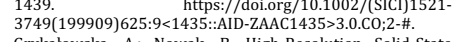

(73) Grykałowska, A.; Nowak, B. High-Resolution Solid-State
$1195 n$ and 195Pt NMR Studies of MPtsn Semiconductors (M=Ti, Zr, Hf, Th). Solid State Nucl. Magn, Reson. 2015, 27 (4),

(74) Lock, H.; Xiong, J.; Wen, Y.C.; Parkinson, B. A.; Maciel, G. (3), 118-129. https://doi.org/10.1006/snmr.2001.0036.

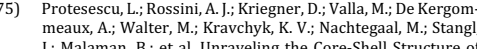
1;: Malaman, Bi; et al. Unraveling the Core-Shell Structure of
Ligand-Capped Sn Snox Nanoparticles by Surface-Enhanced tion Spectroscopies. ACS Nano 2014, 8 (3), 2639-2648 https://doi.org/10.1021/nn406344n.

P.: Waterfield P. P. C. Solid-State NMR Studies of Some Tin (II) Compounds. Recent Adv. Appl. Solid-State NMR Supercond
Phys. Mol. Biol. 2004, 26 (3), 160-171. Phys. Mol. Biol. 2004, 26 (3),
https://doi.org 10.1016/.jssmm.2004.03.010. Yeh, H-M. M.; Geanangel, R. A. 119Sn NMR Spectra of Tin(II) Halides. Inorganica Chim. Acta 1981, 52, $113-1$
https://doi.org/ $10.1016 / 50020-1693(00) 88583-7$.

(78) Sharp, R. R. Field Dependence of Nuclear Magnetic Relaxation
of $119 \mathrm{Sn}$ in SnCl14, SnBr 4 , and SnI4.J.Chem. Phys. 1974, 60 (3) 1149-1157. https://doi.org/10.1063/1.1681126. tropic Knight Shift of Nuclear Magnetic Resonance in Metallic

Prochowicz, D:; Franckevicius, M:; Cieslak, A. M:; Zakeeruddin S. M.; Gratzel, M.; Lewinski, J. Mechanosynthesis of the Hybri
Perovskite CH3NH3Pbl3: Characterization and the Corre sponding Solar Cell Efficiency. J. Mater. Chem. Mater. Energy
Sustain. 20172-20777.
2015,

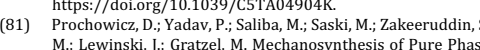


Mixed-Cation MAxFA1-XPbl3 Hybrid Perovskites: Photovol-
taic Perforn taic Performance and Electrochemical Properties. Sustain. En-
ergy Fuels $2017, \quad 1, \quad 689-693$ https://doi.org/10.1039/C75E00094

(82) Saski, M:; Prochowicz, D;; Marynowski, W.; Lewiński, J. Mect FA, Cs-SnX3 $(X=I, B r)$ and Phase-Pure Mixed-Halide MAS nlxBr3-X Perovskites. Eur. J. Inorg. Chem. 2019, 2019 (22)

-

Sum, T. C.; Mathews, N:; García, F; Soo, H. S. Completely S vent-Free Protocols to Access Phase-Pure, Meta Precursor Salts. iScience 2019, 16, 312-325. https://doi.org/10.1016//i.isci.2019.05.042.

(84) Aijouri, Y. F.; Locardi, F.; Gélvez-Rueda, M. C.; Prato, M:; Ses
solo, M.; Ferretti, M:; Grozema, F. C.; Palazon F.; Mechanochemical Synthesis of Sn(II) and Sn(IV) Iodide Peovskites and Study of Their Structural, Chemical, Thermal
Optical, and Electrical Properties. Energy Technol. 190078. https://doi.org/10.1002/ente.20190078.

(85) Xu, j;: Wang, i.; Rall A chanism in Aluminate Melilite La1+XC11-XA1307+05x ramics Synthesized by Glass Crystallization. ACS Appl. Energy https://doiorg/101021/acsaem . 9b00224

$2878-288$

(8) Thurber, K. R. R. Tycko, R. Measurement of Sample Temperatures under Magic-Angle Spinning from the Chemical Shift
and Spin-Lattice Relaxation Rate of $79 \mathrm{Br}$ in KBr Powder.
Magn
Reson

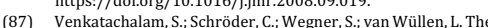
Structure of a Borosilicate and Phosphosilicate Glasses and It
Evolution at Temperatures above the Glass Transition Temperature: Lessons from in Situ MAS NMR. Phys. Chem. Glas.
Eur. I. Glass Sci. AndTechnology Part B 2014, 55 (6). 280-287.

8) Yamada, K.; Kuranaga, Y.; Ueda, K.; Goto, S.; Okuda, T.; Fu-

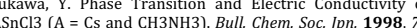
(1), 127-134. https://doi.org/10.1246/bcsi.7.1.127.

(9) Taylor, R. E;; Beckmann, P. A; Bai, S; Dybowski, C. 1271 and ation in Pbl2: A Preliminary Study.J. Phys. Chem. C 2014.,11 (17), 9143-9153. https://doi.org/10.1021/j55023423.

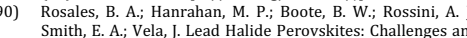
Opportunities in Advanced Synthesis and Spectroscopy. ACS
Energy Lett. 2017, 2 (4), $906-914$.

Mitchell, M. R: Reader, S. W. Johnston, K. E. Pickard, C Whittle, K. R; : Ashbrook, S. E. 1195 Sn MAS NMR and First-Prii(inte Pyro 497. https://doi.org/10.1039/COCP01274B.

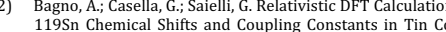
19Sn Chemical Shifts and Coupling Constants in Tin Com-
pounds. J. Chem. Theory Comput. 2006, 2 (1), 37-46 https://doi.org/ $/ 10.1021 /$ ct050173k.
Sharp R R Rotational Diffusin

3) 1195 n in Liquid SnCl4 and Snl4 J. Chem Phys 1972 57 (12) 5321-5330. https://doi.org/10.1063/1.1678224.

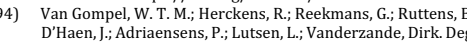
radation of the Formamidinium Cation and the Quantificatio of the Formamidinium-Methylammonium Ratio in Lead Spectroscopy. J. Phys. Chem. C 2018, 122, 4117-4124. https:///aoi.org/10.1021/acs.jpcc.7b09805. mation of Hybrid Perovskite Tin

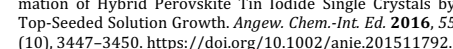

(96) Chung, L.; Song, J.J.H.; Im, Ji; Androulakis, Ji, Malliakas, C. D.; L.j

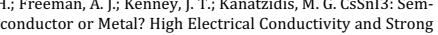
Near-Infrared Photoluminescence from a Single Material
High Hole Mobility and Phase-Transitions. J. Am. Chem. Soc Kofod, P. Lineshapes of a Spin-12 Nucleus with Scalar Cou-
pling to a Quadrupolar Nucleus Subject to Random Field Re ling to a Quadrupolar Nucleus Subject to Random Field 20 .
laxation. I. Magn. Reson. A 1996, 119 (2), 219-224. https://doi.org/10.1006/jmra.1996.0076.

98) Phase Transitions in CSSnCl3 and CSPbBr3 An NMR and NQR

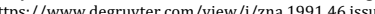
4/zna-1991-0406/zna-1991-0406.xml (accessed Aug 23 , 位ca, Ri; Ferro, P.; Besagni, T:; Calestani, D.; Chiarella, F.; Licci, F. Effect of Humidity on the a.c. Impedance of
CHN3H3SnCl3 Hybrid Films. Appl. Phys. A 2011. 104 (4),

(100) Agashe, C; Major, S. S. Effect of F, Cl and Br Doping on ElectrCal Properties of Sprayed SnO2 Films.J. Mater. Sci. Lett. 19 Bloembergen, N.: Rowland, T.t. On the Nuclear Magnetic Res. onance in Metals and Alloys. Acta Metall. 1953, 1 (6), 731-
746 https://doi.org/10.1016/0001-6160(53)

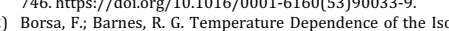
tropic and Anisotropic Knight Shift in Polycrystalline Cad-
mium and $\beta$-Tin. J. Phys. Chem. Solids 1966, 27 (3), 567-573. hitps://doi.org/10.10106/0022-3697(66)902000-9.

(103) Leitens, T; Prasanna, R.; Goldd-Parker, A.; Toney, M. F.;.; McGehee, M. D. Mechanism of Tin oxidation and Stabilization by
Lead Substitution in Tin Halide Perovskites. ACS Energy Lett 2017, 2 (9), 2159-2165. https: //doio.org/10.1021/acsen-
20. ergylett.7b00036.
Korringa, I. Nuclear Magnetic Relaxation and Resonance Line Korringa, I. Nuclear Magnetic Relaxation and Resonance Line
Shift in Metals. Physic 1950, 16 (7), 601-610. hittps://doi.org/

(105) Kowalewski, J,; Maler, L. Nuclear Spin Relaxatition in Liquids:
Theory, Experiments, and Applications, Second Edition hittps://www.crcpress.com/Nuclear-spin-Relaxation-in-Liquids-Theory-Experiments-and-Applications/Kowalewski-
Maler/p/book/97814987782142 (accessed Aug 16, 2019).

(106) Abragam, o. The Principles of Nuclear Magnetism; Clarendon

Press, 1961.
(107) Grutzner, I. Bi: Stewart, K. W.; Wasylishen, R. E.; Lumsden, M.
D.; Dybowski, C.: Beckmann . P. A A N New Mechnonism for Spin-Lattice Relaxation of Heavy Nuclei in the Solid State: 207Pb Relaxation in Lead Nitrate.J. Am. Chem. Soc. 2001, 123

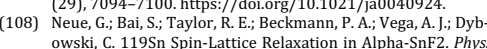

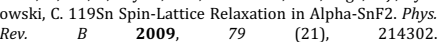
https://doio.org/10.1103/PhysRevB.79.2144302. 9) Shmyreva, A.A.; Safdari, M,; Furó, Li.; Dvinskikh, S. V. NMR Lon-
gitudinal Relaxation Enhancement in Metal Halides by Hetgitudinal Relaxation Enhancement in Metal Haldes by Het-
eronuclear Polarizaztion Exchange during Magi-chngle spin-
ning. J. Chem. Phys. 2016, 144 (22), 224201. CH3NH3). Bull. Chem. Soc. Jpn. 1988, 61 (12), 4265-4268.

(111) Onoda-Yamamuro, $\mathrm{N}$ : Matsuo $\mathrm{T}$. Suga, H. Thermal, Electric, and Dielectric Properties of CH3NH3SnBr3 at Low Tempera-
tures. J. Chem. Thermodyn. 1991, 23 (10), 987-999. Yamada, K; Kawaguchi, H;; Matsui, T.; Okuda, T.; Ichiba, Structural Phase Transition and Electrical Conductivity of the Soc. Jpn. 1990, 63 (9) 2521-2525. soc. $J p h n, 1990, \quad 63$
https: //doio.org/10.1246/bcsi.63.2521.
(113) Van Kranendonk, J.; Walker, M. Theory of Quadrupolar Nunon Processes. Phys. Rev. Lett. 1967, 18 (17), 701-703. https://doio.org/10.1103/PhysRevLett.18.701.

(114) Pérez-OSorio, M. A.; Lin, Q; Phillips, R. T.; Milot, R. L.; Herz, L.
M.; Johnston, M. Bi; Giustino, F. Raman Spectrum of the Or ganic-Inorganic Halide Perovskite $\mathrm{CH}_{3} \mathrm{NH} 3 \mathrm{~Pb} 33$ from First Principles and High-Resolution Low-Temperature Raman
Measurements. . Phys. Chem.C C2018, 122 (38), 21703-21717. https://doi.org/10.1021/acs.jpcc.8b04669.

15) Kusu, T. A. Ionic Conductivity of SnI2. Solid State lon. 1986,20
https: / doi.org/10.1016/0167-

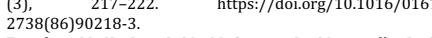

(116) Futscher, M. H.; Lee, J. M.; McGovern, L; Muscarella, L. A.

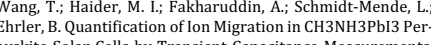
skite Solar Cells by Transient Capacitance Measurements.
ater. Horiz. 2019. https://doi.org/10.1039/C9MH00445A. (17) Ansel, D.; Debuigne, I.; Denes, G;; Pannetier, J; Lucas, J. Abo
SnF2 Stannous Fluoride V. Conduction Characteristics Be ichte Bunsenges. Für Phys. Chem. 1978, 82 (4), 376-380.

(118) Shi, T;: Zhang, H.-S: Meng, W.; Teng, Q; Liu, M.: Yang, X.; Yan,

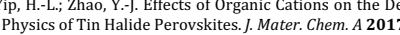

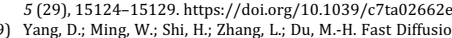
of Native Defects and Impurities in Perovskite Solar Cell Ma-
terial CH3NH3Pbl3. Chem. Mater. 2016, 28 (12), 4349-4357.

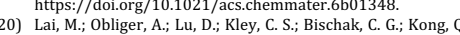
Lei, T.; Dou, Li; Ginsberg, N. S.; Limmer, D. T.; et al. Intrins a Soft Lattice. Proc. Natt. Acad. Sci. 2018, 115 (47), 1192911934. https://doi.org/10.1073/pnas.1812718115.

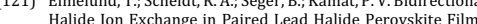
with Thermal Activation. ACS Energy Lett. 2019, 4 (8), 1961 - 
${ }^{119} \mathrm{~S} n$ solid-state NMR

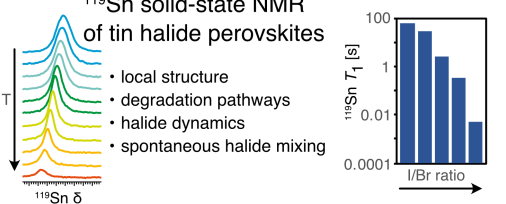

